\title{
Cordonnier Grade 3 Fungal Complication, Proven or Probable Aspergillus Pneumonia
}

National Cancer Institute

\section{Source}

National Cancer Institute. Cordonnier Grade 3 Fungal Complication, Proven or Probable Aspergillus Pneumonia. NCI Thesaurus. Code C138303.

Any proven or probable Aspergillus pneumonia. 